\title{
O CARÁTER REPRESSIVO NA LEGISLAÇÃO SOBRE ABORTO NO BRASIL
}

\section{THE REPRESSIVE CARACTHER IN LEGISLATION ON ABORTION IN BRAZIL}

\author{
Rogério Sganzerla \\ Doutorando em Sociologia e Direito pela UFF, Mestre em Direito pela UNIRIO. \\ Licenciado em Filosofia pela UNIRIO. Pesquisador CJUS/FGV. \\ E-mail: rogeriosganzerla@gmail.com \\ Eder Fernandes Monica \\ Professor adjunto da Faculdade de Direito da Universidade Federal Fluminense. Professor \\ dos Programas de Pós-Graduação em Sociologia e Direito e em Justiça Administrativa. \\ Coordenador do Grupo de Pesquisa Sexualidade, Direito e Democracia. \\ E-mail: ederfm@id.uff.br
}

Recebido em: 12/04/2017

Aprovado em: 07/12/2017

RESUMO: O aumento do número de proposições legislativas no Congresso Nacional evidencia um interesse cada vez maior na regulação da sociedade através do ordenamento jurídico. A pergunta motivadora do presente estudo é: como se dá a produção legislativa no Brasil sobre o tema aborto? A fim de entender este cenário, foram investigados 156 projetos de lei entre 1949 e 2017 sobre aborto, categorizados em razão dos seus temas, tipo de proposição, ano de apresentação e outras variáveis. A intenção é verificar como os projetos se comportam durante a história legislativa brasileira e sobre quais temas eles discutem. A conclusão é que, no tema do aborto, o Poder Legislativo brasileiro ainda é bastante repressivo na regulação da sexualidade ao passo que grande parte da sua produção diz respeito a projetos envolvendo o aspecto criminal do aborto e somente 11 projetos tratarem de políticas públicas de prevenção/informação/intervenção especificamente para as mulheres. Mais ainda, tendo em 38 anos qualquer projeto sido transformado em lei ou chegado ao Plenário da Câmara dos Deputados, o fato de uma proposta de emenda constitucional ter chegado ao Plenário em 2017 para restringir completamente qualquer tipo de aborto evidencia um Poder Legislativo ainda vinculado à legitimação de uma sexualidade hegemônica e um ataque à sexualidade "viciada".

Palavras-chave: Aborto; Congresso Nacional; Câmara dos Deputados; Projetos de Lei; Repressão;

ABSTRACT:The increase in the number of bills in the National Congress shows an increasing interest in the regulation of society through the legal system. The question of the present study is: how does the legislative production in Brazil take place on abortion? In order to understand this scenario, 156 bills were investigated between 1949 and 2017 on abortion, categorized by topics, type of proposition, year of presentation, and other variables. The intention is to verify how the projects behave during the Brazilian legislative history and on what topics they discuss. The conclusion is that in the subject of abortion, the Brazilian Legislative Branch is still quite repressive in the regulation of sexuality, while a large part of its production concerns projects involving the criminal aspect of abortion and only 11 projects deals with public policies 
prevention/information /intervention specifically for women. Moreover, knowing that in 38 years any bill turned into law or reached the Plenary of the Chamber of Deputies, the fact that a constitutional amendment reached the Plenary in 2017 to completely restrict any type of abortion evidences a Legislative still bound to the legitimization of a hegemonic sexuality and an attack on a "addicted" sexuality.

Keywords: Abortion; National Congress; Chamber of Deputies; Bills; Repression

SUMÁRIO: $1 . \quad$ INTRODUÇÃO; $\quad 2$. NOTAS METODOLÓGICAS; 3 . O CENÁRIO BRASILEIRO DA LEGISLAÇÃO SOBRE ABORTO NO BRASIL; 4.A REPRESSIVIDADE NA HISTÓRIA DA SEXUALIDADE; CONCLUSÃO; BIBLIOGRAFIA

\section{INTRODUÇÃO}

De que forma o aborto é discutido no Poder Legislativo do Brasil?Essa pergunta se justifica na medida em que o tema está cada vez mais presente na pauta de discussões do Brasil e do mundo. Com as discussões recentes em torno da violência de gênero e dos direitos das mulheres, é importante se questionar como os direitos reprodutivos das mulheres estão sendo abordados no Congresso Nacional do Brasil ${ }^{1}$. Ao Presidente da República é vedado editar qualquer tipo de medida provisória sobre matéria de direito penal, processual penal e processual civil $^{2}$, inclusive sob delegação de competência exclusiva do Congresso Nacional ou privativa da Câmara dos Deputados ou do Senado federal ${ }^{3}$. Portanto, legislar sobre o tema aborto é de competência privativa da União através do Congresso Nacional ${ }^{4}$.

Sendo assim, é importante investigar como a legislação sobre o aborto no Brasil se desenvolveu no decorrer da sua história e quais as perspectivas futuras para o tema. Trata-se de um ponto importante para entender qual o estado atual normativo brasileiro sobre os direitos reprodutivos das mulheres.

A pesquisa "Aborto no Congresso Nacional" nasceu em 2015 através de uma análise do Poder Legislativo para dissertação de mestrado acadêmico. Em 2016, esta pesquisa foi aprimorada em contato com o Grupo de Pesquisa da UFF "Sexualidade, Direito \& Democracia"6, sob orientação do Professor Eder Fernandes Monica. Em 2017, a pesquisa foi incorporada ao projeto "Congresso em Números"" da Escola de Direito, em parceria com a Escola de Matemática Aplicada (EMAp), ambos da Fundação Getúlio Vargas do Rio de Janeiro.

A primeira fase desta pesquisa, originada ainda do projeto de dissertação, foi publicada em 2017 na Revista de Direito Administrativo \& Constitucional com o título "Aborto e

\footnotetext{
${ }^{1}$ A referência ao Congresso Nacional remeterá sempre ao Poder Legislativo na união de suas duas Casas: Câmara dos Deputados e Senado Federal, conforme dispõe o art. 44 da CRFB/1988: O Poder Legislativo é exercido pelo Congresso Nacional, que se compõe da Câmara dos Deputados e do Senado Federal.

${ }^{2}$ Art. 62, $\left.\$ 1^{\circ}, \mathrm{I}, \mathrm{b}\right), \mathrm{CRFB} / 1988$ : É vedada a edição de medidas provisórias sobre matéria relativa a direito penal, processual penal e processual civil.

${ }^{3}$ Art. $68, \$ 1^{\circ}$, II, CRFB/1988: Não serão objeto de delegação os atos de competência exclusiva do Congresso Nacional, os de competência privativa da Câmara dos Deputados ou do Senado Federal, a matéria reservada à lei complementar, nem a legislação sobre nacionalidade, cidadania, direitos individuais, políticos e eleitorais;

${ }^{4}$ Art. 22, CFRB/1988: Compete privativamente à União legislar sobre direito civil, comercial, penal, processual, eleitoral, agrário, marítimo, aeronáutico, espacial e do trabalho.

${ }^{5}$ Mais informações: https://www.abortonocongresso.com/

${ }^{6}$ Mais informações: http://www.sdd.uff.br/

7 Mais informações: http://cts.direitorio.fgv.br/data-for-good/congresso-em-numeros/. O projeto Congresso em Números, realizado no âmbito da área Data For Good do Centro de Tecnologia e Sociedade - CTS/FGV, utiliza dados de diferentes instituições, como aqueles produzidos pelo próprio Congresso, o IBGE, o TSE ou mesmo dados anônimos de empresas privadas para avaliar a relação entre os interesses defendidos pelos deputados e senadores e sua base eleitoral. Aplicamos também os mais recentes avanços do campo da matemática e do uso de tecnologias, como a inteligência artificial, para ajudar o Brasil a pensar o seu Parlamento.
} 


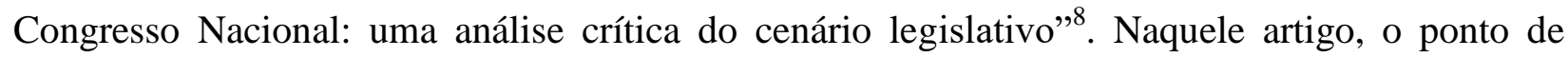
partida foi analisar um diagnóstico de todos os projetos de lei sobre aborto na Câmara dos Deputados e no Senado Federal do Brasil (1949-2014). Foram realizadas diversas análises sobre as comissões, autores, temas e plenário. Contudo, o estudo se conteve na análise estrutural e qualitativa do aborto.

O presente artigo vislumbra seguir um passo adiante, correlacionando os dados obtidos com as teorias feministas e também sob uma visão sociológica e filosófica do caráter repressivo do aborto dentro do Poder Legislativo brasileiro. O recorte em torno da repressividade e permissividade se dará através da análise temporal e temática dos projetos de lei em razão dos seus conteúdos. Além disso, a pesquisa já contará com um refinamento analítico propiciado pelos pesquisadores do Congresso em Números da $\mathrm{EMAp} / \mathrm{FGV}^{9}$ através dos estudos de modelagem aplicados a sistemas complexos. Ainda que num estágio inicial desta nova fase, já é possível perceber as implicações possíveis deste tipo de análise aplicadas aos estudos de gênero e sexualidade, especialmente ligados ao legislativo brasileiro.

No primeiro capítulo serão apresentadas a metodologia e os dados das proposições do Congresso Nacional sobre aborto já sob um recorte analítico repressivo/permissivo. No segundo capítulo, tais dados serão analisados numa perspectiva filosófica sociológica em razão da perspectiva histórica de gênero e sexualidade no Brasil. O artigo conclui que o Congresso Nacional no tema de aborto, ao longo do tempo, tem se posicionado de forma bastante repressiva nas suas proposições legislativas contrariando diversos pactos internacionais de direitos das mulheres e, especialmente, promovendo um retrocesso legislativo de conquistas de direitos reprodutivos das mulheres.

\section{NOTAS METODOLÓGICAS}

Este artigo busca entender como se deu essa mudança legislativa no tema do aborto historicamente e de que forma essas pessoas com poder de agenda são responsáveis por essa mudança. Para isso, foi utilizada a seguinte metodologia, consistente em três grandes etapas: captura dos dados, armazenamento e análise. A Figura 01 detalha o processo de captura e armazenamento dos dados referentes à tramitação das proposições.

A Câmara dos Deputados, atualmente, oferece alguns dados referentes aos seus processos internos via $\mathrm{API}^{10}$ atualizada diariamente. Essa ferramenta permite que qualquer usuário faça requisições restritas à base de dados disponibilizadas. Como as bases não são disponibilizadas integralmente, para se obter a totalidade dos dados é preciso criar um 'raspador' (também conhecido por Scrapper) que faz requisições sistemáticas à API. Dessa maneira, primeiro se obtém todas as proposições ${ }^{11}$ já apresentadas na câmara, para depois capturar as tramitações ${ }^{12}$.

8 SGANZERLA, Rogerio. Aborto e Congresso Nacional: uma análise crítica do cenário legislativo. In: A\&C Revista de Direito Administrativo e Constitucional. Belo Horizonte: Fórum. 2017, ano 17, nº 67, jan./mar. 2017.

${ }^{9}$ Pesquisadores EMAp/FGV: João Carabetta, Alifer Sales e Fernanda Scovino.

${ }^{10}$ Versão utilizada da API (Aplication Programming Interface) para a captura dos dados http://www2.camara.leg.br/transparencia/dados-abertos/dados-abertos-legislativo

${ }^{11} \mathrm{~A}$ endpoint que fornece os dados das proposições é http://www2.camara.leg.br/transparencia/dados-abertos/dadosabertos-legislativo/webservices/proposicoes-1/listarproposicoes

${ }^{12} \mathrm{~A}$ endpoint que fornece os dados de tramitação é http://www2.camara.leg.br/transparencia/dados-abertos/dadosabertos-legislativo/webservices/orgaos/obterandamento 
Figura 01: O processo de captura dos dados de tramitação das proposições disponibilizados pela API da Câmara dos Deputados consiste em duas partes. Em azul, o processo de captura de todas as proposições. Em vermelho, o processo de captura da tramitação de cada proposição. Internamente, ambos processos consistem na mesma sequência de passos para exportar os arquivos XML em um banco SQL.

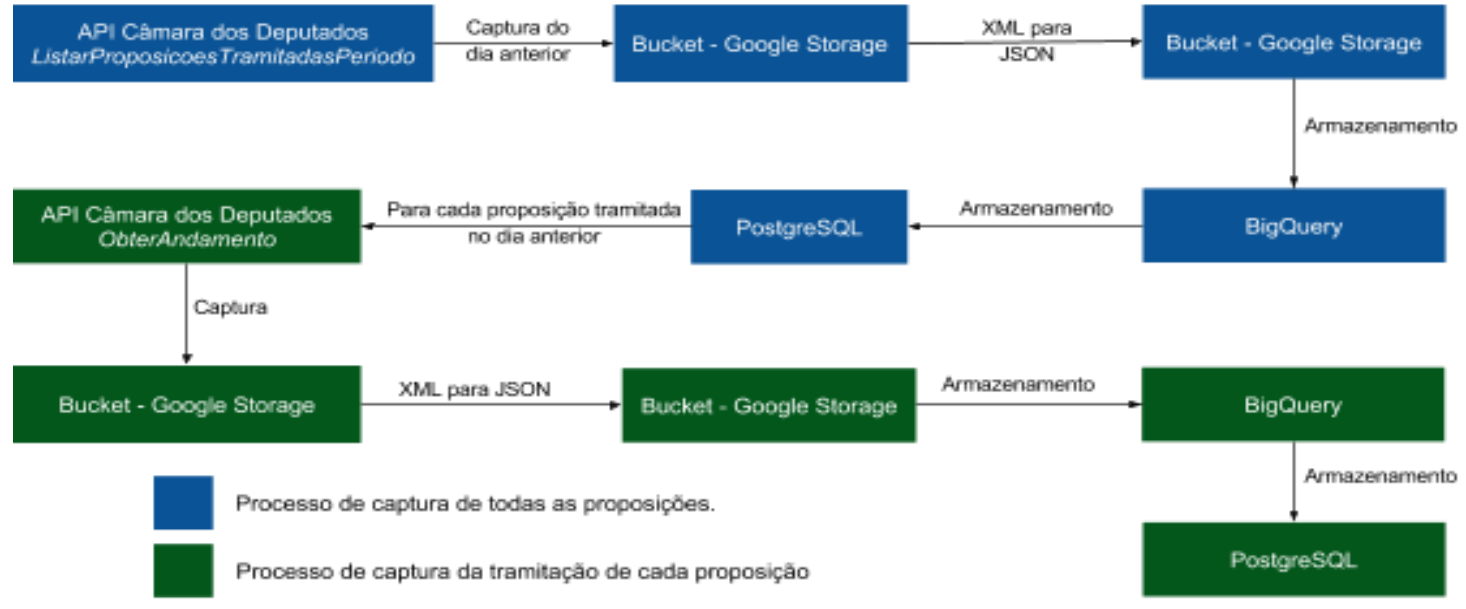

A API devolve um arquivo em XML que foi salvo num sistema de arquivos (no caso o Bucket do Google Cloud) que permite o acesso à informação não processada. A seguir, os arquivos foram inseridos em uma base de dados relacional PostgreSQL.

A base de dados disponibilizadapermite que apenas os projetos posteriores ao ano de 2001 ou que tiveram algum tipo de tramitação após esse período estão disponíveis com inteiro teor dos projetos de lei. Na prática, a abrangência temporal dos dados compreende a data do primeiro projeto sobre o tema, datado de 30 de setembro de 1949 até a data de 27 de novembro de 2017. Compreende-se então todo o período de desenvolvimento de uma legislação genuinamente nacional a respeito do aborto, incluindo na análise os períodos de silêncio legislativo a respeito da temática, pois são dados importantes para a percepção da evolução da política sexual sobre o aborto no Brasil.

Os termos de busca para as pesquisas foram "aborto", "nascituro", "concepção", "interrupção da gravidez" e os documentos consultados foram os que pretendiam alterar o ordenamento jurídico, quais sejam projetos de lei (PL), por projetos de decreto legislativo (PDC), por projetos de lei complementar (PLP) e por projetos de emenda à constituição (PEC), com a exclusão de requerimentos, ofícios e outros tipos. O tratamento nominativo - como professor, doutor, pastor, delegado - dos parlamentares foi desconsiderado, pois poderiam influir na avaliação dos dados.

Do total, com a exclusão de projetos não relacionados diretamente com o tema, chegouse ao número de 156 projetos na Câmara e 9 no Senado. A análise foi dividida em três vertentes: justificativa do projeto, pareceres dos relatores nas Comissões e votos em separado nas Comissões. Caso o projeto de lei tivesse qualquer projeto apensado a ele, o principal seria chamado "raiz".

Todos os projetos encontrados na Câmara dos Deputados foram divididos em 12 grupos: (i) medicamentos $^{13}$, (ii) estatuto do nascituro ${ }^{14}$; (iii) tipificação de novos crimes ${ }^{15}$; (iv)

${ }^{13} \mathrm{O}$ critério usado para classificação do grupo "medicamentos" foi o projeto abordar qualquer o uso de medicamentos que influenciassem no aborto.

${ }_{15}^{14} \mathrm{O}$ critério usado para classificação do grupo "estatuto do nascituro" foi o projeto abordar o estatuto do nascituro.

${ }^{15} \mathrm{O}$ critério usado para classificação do grupo "tipificação de novos crimes" foi o projeto criminalizar nova conduta das atuais previstas na legislação penal. 
descriminalização do aborto $^{16}$; (v) aumento/agravamento de pena ${ }^{17}$ (vi) novas hipóteses/revogação do aborto legal (art. 128, CP) ${ }^{18}$; (vii) disque ${ }^{19}$; (viii) registro público de gravidez $^{20}$; (ix) programas públicos de intervenção/informação/prevenção do aborto ${ }^{21}$; (x) manipulação genética ${ }^{22}$ e (xi) planejamento familiar ${ }^{23}$ e (xii) temas não relacionados ${ }^{24}$.

Foi classificado como projeto contra o aborto qualquer projeto que pretendesse a restrição de direitos da mulher, valorização do bem jurídico vida (em detrimento da liberdade da mulher), criminalização do aborto, aumento da pena, entre diversos outros que tivessem objeto similar. Já os projetos a favor do aborto foram entendidos como aqueles que tinham a pretensão de valorização da liberdade mulher em detrimento da vida do feto, assim como diversos outros com objetos similares. De forma a estruturar melhor a análise da questão, foram determinadas três etapas de análise: a primeira com base nas informações processuais dos projetos de lei, tais como ano de apresentação, tempo de tramitação, autores, relatores, partidos, motivo de arquivamento e comissões passadas; a segunda comparando o tipo de manifestação dos relatores com o colegiado nas Comissões de Seguridade Social e Família (CSSF) e Comissão de Constituição e Justiça e de Cidadania (CCJC); a terceira com base no agrupamento temático dos projetos de lei em razão dos assuntos abordados.

\section{O CENÁRIO BRASILEIRO DA LEGISLAÇÃO SOBRE ABORTO NO BRASIL}

A pesquisa “Aborto no Congresso Nacional” nasceu diante de uma necessidade prática de investigação estrutural e conjuntural do Poder Legislativo no Brasil. Dessa forma, as investigações não buscam captar projetos de lei específicos e sua tramitação como foco único, mas sim, extrair e organizar bases de dados que auxiliem a produzir melhor entendimento sobre a atuação do Congresso Nacional, bem como tornar essas bases acessíveis e apresentar análises, estudos e ferramentas para permitir que pesquisadores e toda a sociedade possam avaliar e propor melhorias para o Parlamento brasileiro.

\footnotetext{
${ }^{16} \mathrm{O}$ critério usado para a classificação do grupo "descriminalização do aborto" foi o projeto abordar a interrupção da gravidez ou a supressão do art. 124 do Código Penal. Também foi incluído neste tópico o plebiscito sobre o aborto praticado por médico por entender que o projeto, ao analisar se o aborto praticado por médico deve ou não ser criminalizado, aborda uma hipótese de descriminalização específica da prática do aborto.Como não seria uma condição específica da mulher especificada no art. 128 do Código Penal, preferiu-se enquadrá-lo neste grupo.

${ }^{17} \mathrm{O}$ critério usado para classificação do grupo "aumento/agravamento de pena" foi o projeto propor uma majoração da pena do crime de aborto ou propor um agravamento no tratamento da conduta.

${ }^{18} \mathrm{O}$ critério usado para classificação do grupo "novas hipóteses/revogação do aborto legal" foi o projeto abordar o art. 128 do Código Penal no tocante a novas hipóteses de aborto legal ou propondo a sua revogação.

${ }^{19} \mathrm{O}$ critério usado para classificação do grupo "disque" foi o projeto propor a criação de um disque sobre o aborto. No caso, duas foram as hipóteses: disque denúncia e disque informações.

${ }^{20} \mathrm{O}$ critério usado para classificação do grupo "registro público de gravidez" foi o projeto propor um registro público de mulheres grávidas como forma de reduzir a prática ilícita do aborto.

${ }^{21}$ O critério usado para classificação do grupo "programas públicos de intervenção/informação/ prevenção do aborto" foi o projeto abordar uma política pública específica sobre o aborto, seja para a mulher ou para o nascituro, no tocante as suas causas ou consequências, abrangendo qualquer tipo de projeto que fizesse alusão à prevenção, informação ou que intervisse sobre o procedimento abortivo.

${ }^{22} \mathrm{O}$ critério usado no grupo "manipulação genética" foi o projeto abordar especificamente a manipulação genética.

${ }^{23}$ O critério usado no grupo "planejamento familiar" foi o projeto abordar no seu título ou ementa qualquer referência a ações que tenham como finalidade o planejamento familiar.

${ }^{24}$ Não possuem uma relação direta com a questão do aborto. Tal relação direta se traduz em qualquer matéria que discuta questões, métodos ou processos que abarquem o feto, nascituro, a relação filho e mãe ou similar, contanto que faça referência explícita a qualquer um dos sujeitos anteriormente descritos, desde que envolva uma situação de antecipação (dolosa ou culposa) da gravidez.
} 
Tomando como base as análises do pesquisador Acir Almeida sobre sistemas complexos adaptativos do legislativo ${ }^{25}$, parte-se do princípio que há diversos arranjos institucionais dentro do legislativo que são auto impostos pelos legisladores e solucionam problemas coletivos ao restringir o uso de seus direitos a fim de gerar ordem e efetividade a um órgão que, de outra maneira, seria caótico. Esse caos deriva de um estado de natureza completamente caracterizado por uma regra da maioria prevalece (instáveis e qualquer uma das opções de escolha pode ser obtida) e também por frágeis barganhas legislativas (em termos de durabilidade e fragilidade), levando à paralisia, incerteza e decisões cíclicas. Logo, esse arranjo institucional faz com que os legisladores atuem de forma organizada.

Porém, como fazer para que determinada mudança legislativa ocorra? Primeiramente, é preciso ter em mente qual o tipo de modelo de definição da agenda. Há dois modelos ideais: o modelo de comissão, no qual os poderes de agenda são dispersos por comissões parlamentares autônomas, cada uma com um monopólio sobre um conjunto de áreas de políticas públicas; e o modelo de partido-cartel, no qual os poderes são concentrados nas mãos da liderança do partido majoritário. O que acontece na prática é que a maioria das legislaturas democráticas modernas se encaixa em algum lugar entre estes dois extremos (Mattson e Strom, 1995).

No modelo adotado pelo Brasil, a agenda é definida em grande parte pelos Líderes, pelo Presidente das Casas (Câmara dos Deputados e Senado Federal) e pelo Presidente das Comissões. O/a Presidente da Câmara dos Deputados é uma pessoa que detém grande poder de decisão em suas mãos. A Presidência da Câmara faz parte da Mesa, a qual, na qualidade de Comissão Diretora, incumbe a direção dos trabalhos legislativos e dos serviços administrativos da Câmara (art. 14, RICD). Logo, trata-se do cargo máximo do órgão central na determinação de pauta, prazos e decisão de questões de ordem e as reclamações. Além disso, em caso de impedimento do Presidente e do Vice-Presidente, ou vacância dos respectivos cargos, o/a Presidente da Câmara dos Deputados é o/a próximo na linha sucessória da Presidência da República (art. 80, CRFB/1988).

Ao Presidente da Câmara dos Deputados cabe, entre outras prerrogativas, a organização, ouvido o Colégio de Líderes, da agenda com a previsão das proposições a serem apreciadas no mês subsequente, para distribuição aos Deputados (art. 17, I, s, RICD), bem como organizar e designar a Ordem do Dia das sessões, na conformidade da agenda mensal (art. 17, I, t, e art. 86, RICD $)^{26}$. As sessões ordinárias terão duração de 5 horas, contendo a Ordem do Dia iniciada às 16h, com duração de 3h prorrogáveis, para apreciação da pauta (art. 66, III, RICD). Cabe ao Presidente dar conhecimento da existência de projetos de lei constantes da pauta e aprovados conclusivamente pelas Comissões Permanentes ou Especiais, para eventual apresentação de recurso (art. 82, I, RICD), e dar início à apreciação da pauta (art 83, RICD). Assim como nas Comissões, findo o tempo da sessão, o Presidente anunciará a Ordem do Dia da sessão de deliberação seguinte, dando ciência às Lideranças (art. 85, RICD).

Nas comissões, o Presidente de Comissão é também um cargo importante na determinação da agenda. Seu procedimento de eleição é o mesmo do Presidente da Câmara: maioria absoluta de votos em primeira rodada e maioria simples, presente a maioria absoluta, em segunda rodada. Assim como na Câmara, cabe a/ao Presidente de Comissão dar à Comissão e às Lideranças conhecimento da pauta das reuniões (art. 41, V, RICD) e, finda a hora dos trabalhos, anunciar a Ordem do Dia da reunião seguinte (art. 47, p.u. RICD). A seu juízo também cabe a duração do tempo necessário de exame da pauta (art. 46, §6 $6^{\circ}$ RICD).

\footnotetext{
${ }^{25}$ Almeida, Acir. Superando o caos: legislativos como sistemas complexos adaptativos. In: Bernardo Alves Furtado; Patrícia A. M. Sakowski; Marina H. Tóvolli. (Org.).Modelagem de sistemas complexos para políticas públicas. 1ed.Brasília: IPEA, 2015, v. 1, p. 375-401.

${ }^{26}$ Para que uma proposição esteja apta para pauta e na Ordem do Dia é preciso que esteja em condições regimentais e com os pareceres das Comissões a que foi distribuída (art. 86, §3, RICD).
} 
Portanto, como dito, para que uma mudança legislativa ocorra, pessoas com poder de agenda são essenciais neste processo. No Brasil, à primeira vista, cabe ao Presidente a organização e elaboração da agenda mensal e da Ordem do Dia. Porém, estão também envolvidos nesta tarefa o Colégio de Líderes, constituído pelos Líderes da Maioria, da Minoria, dos Partidos, dos Blocos Parlamentares e do Governo (art. 20, RICD).

Mas de que forma essa mudança pode ser feita por esses atores?

Alterações no cenário legislativo que tratem do tema aborto podem ser feitas por projetos de lei (PL), por projetos de decreto legislativo (PDC), por projetos de lei complementar (PLP) e por projetos de emenda à constituição (PEC). Sua aprovação varia principalmente em razão do quórum de votação, turno e alteração no ordenamento jurídico. Eles seguem a mesma premissa: quanto mais importante e hierárquica for a alteração do sistema jurídico maior será a necessidade de quórum para sua aprovação. Nesse sentido, projetos de emenda à Constituição exigem 3/5 dos membros em 2 turnos, projetos de lei complementar maioria absoluta em 2 turnos, e projetos de lei e medidas provisórias apenas maioria simples, em turno único. Quanto maior o nível hierárquico, maior o quórum e mais turnos.

\begin{tabular}{|c|c|c|c|}
\hline Tipo de Projeto & \multicolumn{2}{|c|}{ Turnos (CD-SF) } & $\begin{array}{c}\text { Quórum aprovação } \\
\text { (Deputados-Senadores) }\end{array}$ \\
\hline Emenda à Constituição (PEC) & 2 & 2 & 3/5 (308D- 49S) \\
\hline Lei complementar (PLP) & 2 & 1 & Maioria absoluta (257D - 41S) \\
\hline Lei (PL) & \multicolumn{2}{|c|}{1} & $\begin{array}{c}\text { Maioria simples, } \\
\text { presente a maioria absoluta } \\
\text { (min 129 de 257D e 21 de 41S presentes) }\end{array}$ \\
\hline
\end{tabular}

No tema do aborto, dos 155 projetos investigados pela pesquisa (1949-2017), 7 são projetos de emenda à constituição (PEC), 11 são projetos de decreto legislativo (PDC), 1 é projeto de lei complementar (PLP) e 136 são projetos de lei (PL). Em todo este tempo (68 anos), apenas três foram transformados em lei: dois deles tratam de questões envolvendo direitos trabalhistas (Lei ${ }^{\circ}$ 8.921/1994) e planos de saúde (Lei $n^{\circ} 11.935 / 2009$ ). O terceiro trata do delito de aborto (PL 2.275/1979), que chegou ao Plenário Câmara e foi transformado na Lei $\mathrm{n}^{\circ}$ 6734/1979. Ele alterava a Lei de Contravenções Penais ao excluir a expressão "ou evitar a gravidez" como causa de punição para o anunciante de processo, substância ou objeto destinado a provocar aborto.

Em 2017, diante da aprovação da PEC 181/2015 em Comissão Especial, o tema ficou ainda mais em voga. A redação original deste projeto alterava somente a licença maternidade em caso de parto prematuro.O relator do projeto na Comissão Especial, deputado Jorge Tadeu Mudalen (DEM/SP), apresentou um substitutivo acrescentando a "inviolabilidade do direito à vida desde a concepção". Na prática, isso proíbe todos os tipos de aborto, inclusive os autorizados hoje pela legislação e pelo Supremo Tribuna Federal (STF). Ao fazer isso, a Comissão Especial, de forma relâmpago, retrocedeu um debate que estava travado desde 1949: apenas um projeto chegou ao Plenário ${ }^{27}$ da Câmara dos Deputados no debate sobre o crime de aborto, em 1979.

${ }^{27}$ Cada uma das Casas do Poder Legislativo possui Comissões Parlamentares, Permanentes ou Temporárias, com funções legislativas e fiscalizadoras. As Comissões promovem, também, debates e discussões com a participação da sociedade em geral, sobre todos os temas ou assuntos de seu interesse. É também no seu âmbito que são apresentados e estudados todos os dados, antecedentes, circunstâncias e conveniência de um projeto. Nas Comissões se possibilita que esses aspectos sofram ampla discussão e haja mais liberdade para expressão das opiniões e formação do consenso que, emitido sob a forma de parecer da Comissão, irá orientar o Plenário na apreciação da matéria. São duas as formas de apreciação: (i) conclusiva, quando os projetos são apreciados somente pelas Comissões, que têm o poder de aprová-los ou rejeitá-los, sem ouvir o Plenário; e (ii) realizada pelo 
Desde 1979, 7 Projetos de Emenda Constitucional (PEC) já tentaram incluir a expressão "desde a concepção" para proteção do direito à vida. Cinco se encontram arquivados e um está aguardando parecer na CCJC. Ainda assim, nenhum deles, até 2017, sejam PLs, sejam PECs, tina chegado ao Plenário da Câmara dos Deputados desde 1979. A PEC 181/2015 quebrou este paradigma de quase 38 anos.

Pergunta-se: por que esta escrita é tão significativa, especialmente para projetos envolvendo aborto?

Do total de 155 projetos na Câmara dos Deputados, 82 foram apresentados depois de 2003, cerca de $53 \%$ do total. Por outro lado, é possível notar que até 1988, as apresentações de projetos sobre o tema correspondem apenas a 13\%. Além disso, há uma tendência: tomando como base os anos de eleição para a Câmara dos Deputados (1994, 1998, 2002, 2006 e 2010), a apresentação de projetos sobre o tema nesses anos é quase nula e tende a crescer nos três anos seguintes. Nos anos de 2003 e 2007, (em tese) primeiro ano de legislatura dos (novos) Deputados, o número foi muito acima do normal, seguindo a mesma tendência em 2005.

Logo, nota-se que há três comportamentos em destaque: i) antes da Constituição Federal de 1988 o tema do aborto praticamente não era pauta no cenário legislativo; ii) de 1988 a 1990 há um aumento expressivo do número de proposições, mas que diminui novamente em 1991; iii) após os anos 2000, este tema representa mais da metade das proposições. Assim, três perguntas podem ser feitas diante destes três cenários distintos: porque não havia quase interesse antes de 1988, porque houve esse pico de interesse entre 1988 a 1990 e porque o interesse aumentou nos $\operatorname{anos} 2000$ ?

Gráfico 01 - Quantidade de proposições por ano na Câmara dos Deputados

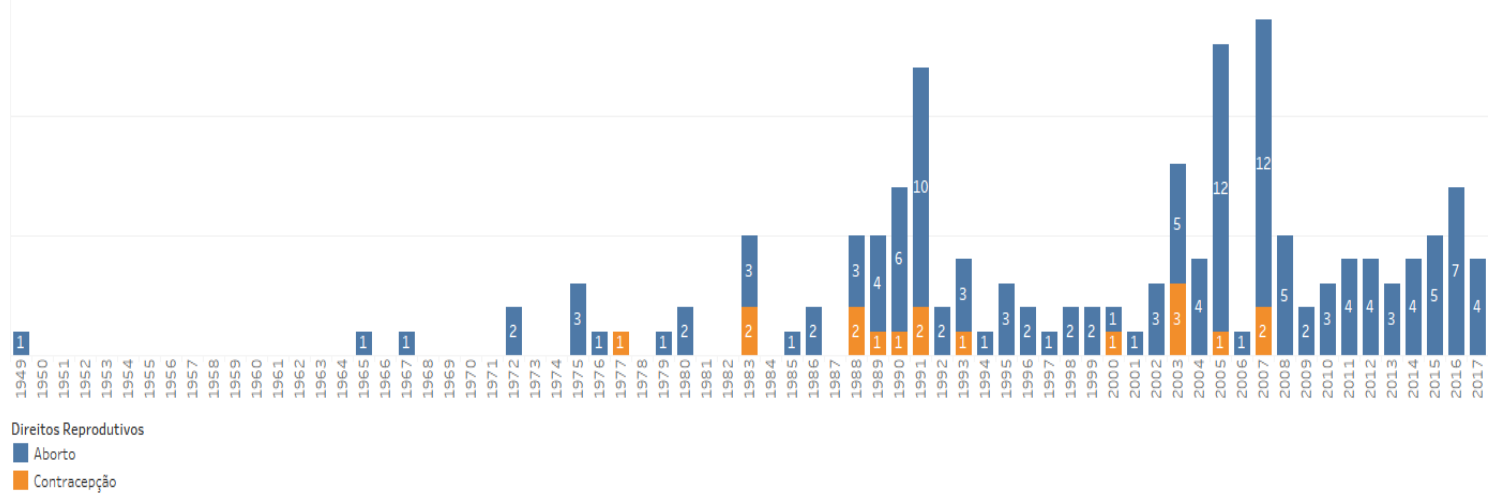

Para entender melhor a dinâmica das proposições e como elas se comportam temporalmente, foi realizada uma categorização em razão das suas temáticas. Cada projeto foi indexado a um grupo de acordo o tema principal discutido, mas poderia aparecer repetido em outros grupos caso abordasse tais temas de forma subsidiária. O gráfico a seguir representa a organização dos projetos nos grupos por tema principal e secundário. Logo, há projetos que estão em mais de um grupo. Tal representação leva em consideração o tema primário e secundário, fazendo com que o número total de temas representados seja maior que o número total de projetos. Em consequência, como o parâmetro de classificação são as matérias trazidas nos seus conteúdos e não o total de projetos, não se deve confundir a percentagem dos temas com a percentagem sobre o total de projetos de lei apresentados sobre o aborto. Por exemplo, ao afirmar que o grupo (iii) "tipificação de novos crimes" representa $11 \%$, significa dizer que este grupo, cujos dezesseis (16) projetos abordam esse tema (de forma primária ou secundária), corresponde

Plenário propriamente dita, quando este é quem dá a palavra final sobre o projeto, após a análise das comissões. De forma geral, os projetos que afetam direitos constitucionais mais delicados, como o direito à vida e à liberdade, entre outros, deverão passar pelo o crivo do Plenário (Texto retirado do site da Câmara dos Deputados, disponível em http://www2.camara.leg.br/atividade-legislativa/comissoes/o-papel-das-comissoes) 
a $11 \%$ do total assuntos previstos. Ainda assim, por mais que percentualmente não possa ser feita esta correlação, em termos absolutos é possível afirmar que dezesseis (16) projetos de lei do total previam a criminalização de uma nova conduta além das atuais previstas na legislação penal. Desse modo, não necessariamente o aumento dos debates pode ensejar uma posição progressista a respeito do aborto, dentro de todas as tensões possíveis nos embates políticos.

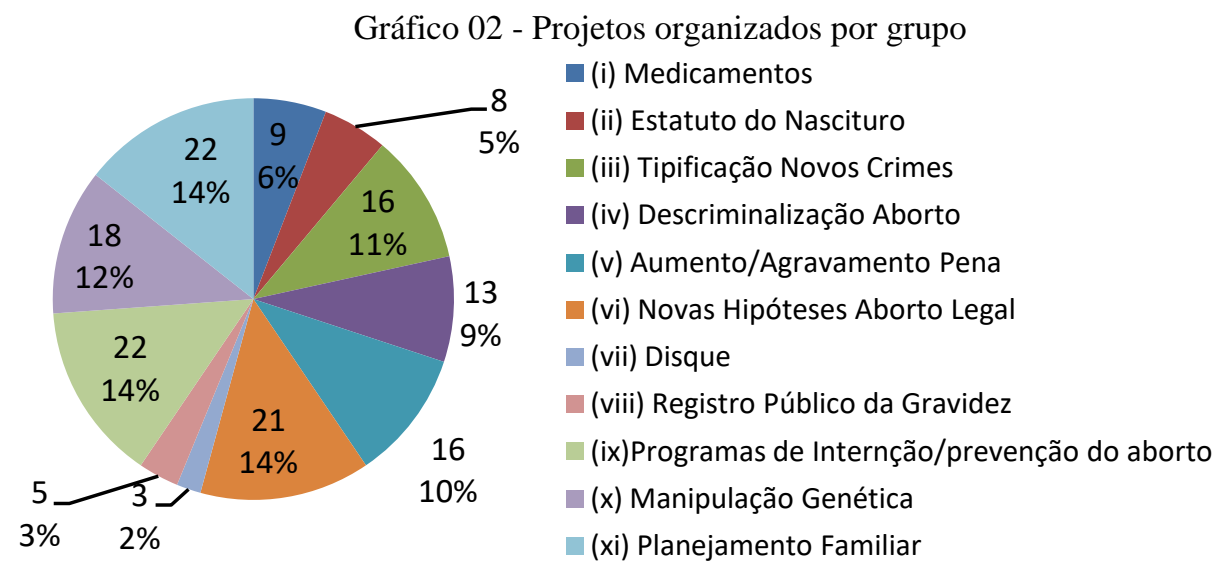

A maior parte dos projetos envolve questões de "novas hipóteses de aborto legal", "programas de intervenção/prevenção do aborto" e "planejamento familiar". O grupo "manipulação genética", apesar de significativamente representado, não trata de forma substancial e dominante a questão do aborto, sendo um conteúdo que será desconsiderado nas análises a seguir. Retirando os $12 \%$ que o grupo "manipulação genética" representa, tem-se um total de $88 \%$. Metade dos temas restantes (44\%) se refere ao aspecto criminal do aborto (grupos iii, iv, v e vi) e a outra metade se refere a políticas públicas sobre aborto, não voltadas somente para o aspecto criminal do aborto (grupos i, ii, vii, viii, ix, xi).

Apesar dessa situação parecer progressista, do ponto de vista do aumento de autonomia corporal para a mulher, há alguns problemas envolvidos. Ainda que sejam políticas púbicas sobre aborto, não são especificamente voltadas para a mulher. Pode-se dizer que os grupos "estatuto do nascituro", "disque", "medicamentos" e "registro público de gravidez" não têm a intenção de proteger a mulher ou de melhorar a sua saúde. Assim, dos $44 \%$ é possível retirar $16 \%$ referentes a esses grupos, remanescendo $28 \%$. Essa representação associa-se a dois grupos: "programas de intervenção/informação/prevenção do aborto" e "planejamento familiar", cada um deles contendo exatamente vinte e dois (22) projetos e representando, assim, 14\% cada.

Dos quarenta e quatro (44), há também aqueles que são contra o aborto, por mais que tratem de políticas públicas específicas. Por ser mais fácil a associação entre um projeto a favor com uma política pública direcionada para a mulher e um projeto contra com uma política pública direcionada para o feto, serão desconsiderados também aqueles projetos que são contra o aborto. Logo, dos vinte e dois (22) projetos em cada grupo, apenas onze (11) do grupo "programas públicos de intervenção/informação/prevenção do aborto" e quatorze (14) do grupo "planejamento familiar" se dirigem às mulheres.

Isso significa dizer que total de projetos de lei sobre aborto, apenas vinte e cinto (25) abordam políticas públicas específicas para as mulheres. Desses, apenas dezesseis (16) estão em tramitação, sendo sete (07) no grupo "programas públicos de intervenção/informação/prevenção do aborto" e seis (06) do grupo "planejamento familiar". Porém, até o momento, nenhum projeto de lei foi aprovado.

Portanto:

$>44 \%$ dos PLs tratam do aspecto criminal do aborto

○ 16 PLs "tipificação de novos crimes" 
○ 13 PLs "descriminalização do aborto"

- 16 PLs "aumento/agravamento de pena"

○ 21 PLS "novas hipóteses/revogação do aborto legal (art. 128, CP)".

$>$ Apenas 11 PLs tratam de "programas públicos de intervenção/informação/prevenção do aborto"

Em resumo, pode-se verificar que cerca de $55 \%$ dos projetos sobre o tema de aborto foram apresentados depois de 2003 e apenas 17\% deles antes de 1989. Na divisão por grupos temáticos dos conteúdos dos projetos de lei envolvendo aborto, notou-se que $44 \%$ dos temas discutidos nos projetos envolviam o aspecto criminal e apenas vinte e cinto (25) do total de projetos de lei abordam políticas públicas específicas para as mulheres. Desses, dezesseis (16) estão em tramitação e nove (09) estão arquivados. De qualquer forma, até hoje, apenas um projeto foi transformado em lei ordinária (Lei 6734/1979), alterando o art. 20 da Lei de Contravenções Penais sobre "Anunciar processo, substância ou objeto destinado a provocar aborto", retirando a expressão original ao final "ou evitar gravidez".

Essa mesma tendência pode ser também observada no Senado Federal. Apesar de não ter sido abordado até este momento, trata-se de uma situação proposital. Preferiu-se analisar a Câmara dos Deputados, que possui cento e vinte e nove (129) projetos, apresentando um panorama detalhado sobre as preferências e ações dos Deputados para que, somente após, verificar se o mesmo cenário também ocorre no Senado Federal, haja vista que neste há somente nove (09) projetos, número baixo para uma análise mais pormenorizada.

A conclusão sobre essa associação entre Câmara e Senado é, senão igual, de extrema semelhança. Após todas as análises, pode-se concluir e afirmar que tanto o Senado Federal quanto a Câmara dos Deputados, comportam-se como um conjunto, independente do argumento processual legislativo de início de tramitação. Ambos possuem as mesmas competências constitucionais em matéria penal sobre o tema aborto, o que não retira qualquer responsabilidade omissiva sobre as consequências derivadas do presente estudo.

Portanto, neste momento, refaz-se as três perguntas que surgiram no decorrer desta análise: porque não havia quase interesse antes de 1988, porque houve esse pico de interesse entre 1988 a 1990 e porque o interesse aumentou nos anos 2000? Há algumas evidências: i) desde 1979 nenhum projeto foi transformado em norma jurídica e sequer chegou ao Plenário da Câmara dos Deputados; ii) grande parte dos projetos é sobre o aspecto criminal do aborto e eles foram propostos a partir de 1988; iii) todas as proposições a favor do aborto estão arquivadas e algumas daquelas que são contra estão em andamento.

Assim, resta o questionamento: de que forma esse movimento repressivo da sexualidade converge com o movimento do Poder Legislativo brasileiro? Essa pergunta será analisada a seguir.

\section{A REPRESSIVIDADE NA HISTÓRIA DA SEXUALIDADE}

Vive-se uma época de intensa politização da sexualidade. As antigas tensões entre valores religiosos e moralidade social hoje se expressam em debates a respeito das condutas e práticas sexuais, mostrando que disputas sobre valores sexuais implicam disputas por poder (RUBIN, 1993). A sexualidade possui diversos sentidos e definições, a depender da cultura, do momento e da temática analisada. Se ela é um fator social, então se relaciona com as dinâmicas do poder. E quando essas dinâmicas do poder estão em intensa renegociação, a própria dinâmica da sexualidade é questionada e sofre alterações em seus padrões. Uma análise histórica sobre a sexualidade descreve fases de estabilidade e instabilidade do conteúdo das práticas sexuais dentro de padrões que se distinguem hierarquicamente, sendo que a partir de um parâmetro hegemônico de sexualidade, conseguimos encontrar as demais práticas e valores sexuais em uma escala 
decrescente de aceitabilidade social, desde os comportamentos mais aceitáveis até aqueles mais abjetos e reprováveis (BUTLER, 2003).

Cada fase corresponde a períodos que produzem sentidos específicos de moralidade sexual, fornecendo elementos para definirmos os tipos de sexualidade a partir dos momentos históricos e da cultura analisada. Assim, historicamente são construídas sexualidades hegemônicas e sexualidades marginais, dentro de uma política sexual que, a partir de um significado específico de sexualidade, institui formas de regulação das condutas sexuais que refletem as próprias dinâmicas do poder. Aqui nesse estudo, o conceito de sexualidade é amplo, para abarcar as discussões mais específicas tanto sobre direitos reprodutivos, quanto de direitos sexuais, no tocante ao estado atual sobre a política sexual referente ao aborto, preocupando-se com os sujeitos que dão significado à sexualidade, dentro do contexto do sistema representativo democrático parlamentar. O direito e a legislação sexual - que tocam o corpo e a sexualidade humana - são formas específicas de regulação das condutas sexuais e demandam uma análise cuidadosa por serem um dos principais aparatos das dinâmicas de poder, auxiliando significativamente a constituição das políticas sexuais. Dada a objetividade da documentação legislativa e jurisprudencial sobre questões de sexualidade, é possível o desenvolvimento de uma análise sobre políticas sexuais a partir do sistema jurídico-legislativo brasileiro, dentro de uma conjuntura maior de estudos sobre políticas sexuais e sobre a história e as fases da sexualidade moderna, tanto do Ocidente quanto especificamente do Brasil. A própria dinâmica de modificação do conteúdo e sentido dos direitos que se relacionam com o aborto fornece elementos para a melhor compreensão da política sexual de uma determinada cultura.

Dentro de um recorte que compreende o conceito de sexualidade a partir das fases de formação da sociedade moderna, em geral as análises do nosso sistema jurídico-legislativo precisam partir da caracterização do sujeito jurídico moderno dentro do marco do individualismo jurídico e da codificação civil liberal aqui no Brasil, pensando o papel do direito na constituição da subjetividade materializada nas formas possíveis de exercício da sexualidade e da corporalidade. No caso da presente análise, o mapeamento da legislação sobre o aborto fornece uma percepção apurada sobre o controle da corporalidade feminina e a elaboração de políticas sexuais em consequência de determinadas posições políticas expressas na legislação. As perspectivas giram sempre em torno de uma compreensão liberal a respeito do sujeito, com dois grandes focos de tensão: a autonomia corporal da mulher e suas possibilidades de dispor de seu próprio corpo, e a proteção da suposta vida do feto enquanto sujeito também merecedor de proteção. Assim, o ponto inicial de uma análise mais ampla seria o momento em que o direito moderno brasileiro começou a se interessar pela sexualidade, principalmente quando assume uma noção individualista a respeito do sujeito de direitos. E, a partir disso, abre-se a possibilidade de se desenvolver estudos sobre as diversas formas como esse interesse se revelou na nossa legislação e jurisprudência sobre as práticas abortivas. Hipoteticamente, será verificado se, em consonância com pesquisas sobre política sexual no Ocidente, há um aumento da legislação sexual e do controle sobre a corporalidade feminina, evidenciando ao mesmo tempo uma política repressiva, quanto uma política que se abre para a autonomia e autodeterminação da mulher no tocante às práticas abortivas, em um sentido mais progressista.

Desse modo, aliando-se a outras pesquisas sobre a história da sexualidade, é possível perceber que a dinâmica do conceito de sexualidade e sua relação com a legislação sexual é correspondente, ao menos em suas fases, com as dinâmicas experimentadas em outros países do Ocidente (D’EMILIO \& FREEDMAN, 1998), pois nele há um grande investimento histórico em uma determinada concepção de sexualidade dependente de uma organização social baseada em um tipo de família, caracterizada pela heterossexualidade, pela monogamia e pelo privilégio às práticas sexuais orientadas para a procriação. A sexualidade interessante era aquela que proporcionasse a proteção desse núcleo familiar basilar da organização social. Desse modo, o casamento monogâmico e as finalidades de procriação das práticas sexuais eram o principal 
motivo de controle da política sexual, sendo as demais práticas de sexualidade vistas com muita tolerância pelo direito. Mais especificamente, as questões referentes ao matrimônio e sexualidade eram assuntos privados e controlados pela moralidade religiosa, conforme a tradição das Ordenações portuguesas em vigência até o final do século XIX. Com a laicização do Estado e a codificação civil de 1916, uma nova fase de produção de políticas sexuais se inicia, impulsionada pelo novo saber médico que passa a ditar novos saberes disciplinares sobre o corpo e a sexualidade. Essa novidade está presente em muitos âmbitos da sexualidade, pois o há uma nítida e crescente afirmação jurídico-legislativa sobre a sexualidade humana, constatada na legislação e na jurisprudência brasileira. No caso da legislação referente ao aborto, há nítida percepção de um aumento recente das discussões sobre aborto, geralmente ligada às questões de saúde e de planejamento familiar.

No Ocidente, a medicina descobre - ou desenvolve uma nova percepção sobre - o corpo moderno e a sexologia passa a classificar os tipos e comportamentos sexuais, fornecendo padrões de sexualidade aceitável e de patologias comportamentais que envolviam o desejo sexual (ROHDEN, 2003). Aliada a essa noção patológica de sexualidade, toda uma política de higienização social passa a controlar e regular as massas urbanas a partir da normatização da vida sexual. É possível compreender a coincidência da codificação penal liberal da década de 1940 com essa fase de controle demográfico da população. Os Artigos a respeito da prática do aborto recepcionam uma concepção moderna sobre a corporalidade feminina, indicando como caso de escusa quando a mulher está em situação de risco de vida. É também nesse momento histórico do início do século XX que a expressão sexual mais sadia era aquela experimentada dentro dos vínculos matrimoniais, o que também explica a escusa no caso da gravidez decorrente de estupro.

A legislação civil recepciona esse significado de sexualidade e institui políticas sexuais que vigiam moralmente a sexualidade marginal. A partir da noção de sujeito de direito, o sistema jurídico autoriza determinados desejos e repele práticas sexuais dissidentes. Assim, o próprio sistema jurídico afirma a identidade sexual e ajuda na construção histórica das sexualidades marginais, dado o seu papel preponderante em instituir a nova política sexual, agora regulada pelo estado e não mais pela tradição ou pela religião cristã, apesar de sua grande influência, até os dias atuais, na definição do significado da sexualidade, enquanto agente significador. Mesmo que o conteúdo da política sexual continuasse expressando o mesmo sentido que o do sistema de regulação anterior, a forma moderna de regulação - Estado, medicina, psiquiatria, saúde pública e higienismo - já imprime uma dinâmica diferenciada de controle sexual, ao mesmo tempo que desloca para o palco político a sua legitimação, valendo-se de constantes apelos de massa, como proteção à família e à sexualidade das crianças (RUBIN, 1993). É o que se depreende dos debates políticos da metade do século passado em diante em torno do aborto. Há uma sobreposição de argumentos que adentram a esfera política e reivindicam a corporalidade da mulher em nome de outros interesses julgados relevantes.

Essa dinâmica é muito mais intensa, pois se relaciona com o tecnicismo do saber médico. Há uma nítida evolução da política sexual no caso do aborto em se direcionar para políticas públicas de saúde específicas para mulheres, na atualidade. O aprofundamento do saber sobre o corpo humano desenvolvido a partir do século XIX diferencia o corpo masculino e o feminino e revela as particularidades da mulher. Também conhece a respeito das diferenças entre o desejo heterossexual e o homossexual, e encontra modos de explicar a intersexualidade também enquanto questão anatômica. Mesmo preservando a compreensão de uma heterossexualidade enquanto padrão superior (SEDGWICK, 1998), passa a falar de modo mais científico e fornecer dados mais objetivos sobre o corpo e a sexualidade humanas.

A política sexual tende a se pautar nas justificativas científicas para a legitimidade de suas proposições e é criticada a partir de novas formas de política, pautada em movimentos sociais e políticos articulados por meio da identidade sexual. Entram no debate os argumentos dos movimentos feministas e das pautas políticas específicas de uma política promovida em torno da 
identidade feminina e das suas singularidades, sendo que a questão do aborto desde muito tempo é um dos pontos principais dos pleitos dos movimentos feministas. Quanto mais a ciência fala sobre sexualidade, mais se aprofunda o saber sexual e se intensifica o caráter político da sexualidade (BUTLER, 2015), retirando da esfera privada o debate sobre o aborto. Consequentemente, quanto mais a sociedade se entende a partir do marcador da sexualidade, mais o direito e a legislação se posicionam a respeito, gerando uma inflação de legislação sexual. Esse sentido de inflação é notório no grande número de propostas legislativas sobre o aborto.

Em geral, no tocante à sexualidade, sua primeira fase é marcada por uma a legislação sexual de caráter repressivo, preocupada em legitimar a sexualidade hegemônica e atacar sexualidade "viciada". Ela se legitima dentro de uma compreensão de relação da lei com a moralidade da maioria da sociedade, também preocupada com a repressão das condutas sexuais não aceitáveis. A própria legislação reproduzia determinados conceitos repressivos, como obscenidade, sodomia, pudor, dentro de uma ampla preocupação com os desviantes sexuais e com a restrição de liberdades civis em nome da moralidade sexual, comprimindo as fronteiras do comportamento sexual aceitável (RUBIN, 1993). No caso do aborto, até os tempos atuais as discussões possuem um caráter depreciativo, tornando-o assunto desagradável. As próprias defesas em favor da descriminalização tendem a ser lidas como defesas imorais, atentatórias ao pudor público e aos costumes sadios da sociedade. É possível perceber que o aborto é um dos últimos pontos da sexualidade que ainda é lido dentro de uma plataforma de repressão intensa.

Mas com a desestabilização das formas tradicionais de organização da vida cotidiana e familiar, principalmente após a Segunda Guerra Mundial, ocorre um grande processo de desconstrução dos padrões sexuais e de afirmação da sexualidade como o local do desejo livre, onde se realiza a identidade pessoal e onde o sujeito se auto realiza (PRECIADO, 2015). Os sistemas tradicionais, religiosos e modernos passam a coexistir conflituosamente, sendo pressionados pelos diversos atores e movimentos políticos identificados pela sexualidade e pela nova compreensão de democracia e de liberdade, que exige do Estado uma política sexual voltada para a promoção da sexualidade democrática (RIOS, 2006). Várias pautas identitárias unidas pelo denominador da sexualidade exigem do sistema jurídico uma nova compreensão sobre a sexualidade e uma legislação sexual que veicule valores mais fundamentais em relação à liberdade sexual e corporal.

Portanto, diante destas três fases da sexualidade, em quais delas o Poder Legislativo brasileiro se encontra?

\section{CONCLUSÃO}

Verifica-se que o caráter repressivo é bastante presente nos projetos de lei, sejam em trâmite, sejam os arquivados. Até os tempos atuais, as discussões possuem um caráter depreciativo, tornando-o assunto desagradável. As próprias defesas em favor da descriminalização tendem a ser lidas como defesas imorais, atentatórias ao pudor público e aos costumes sadios da sociedade. É possível perceber que o aborto é um dos últimos pontos da sexualidade que ainda é lido dentro de uma plataforma de repressão intensa.

Por um lado, 55\% dos projetos de lei foram apresentados a partir de 2003, demonstrando que há um debate crescente sobre o aborto. O que antes sequer era tornado a público e rechaçado aos bastidores como uma questão imoral e irrelevante, hoje já traz consigo um tema de políticas públicas e autonomia da mulher, saindo da questão pura e simples da criminalização (ou não) do aborto. Por outro lado, nota-se que os temas referentes a liberalização e/ou direitos da mulher foram (e estão) arquivados, tendo um número muito maior de projetos em andamento sobre o caráter repressivo, seja através da "tipificação de novos crimes" quanto do "aumento/agravamento da pena". 
A conclusão é que nos últimos anos vivencia-se um processo de autonomização da sexualidade, desvinculada tanto das tradições, quanto das demandas da medicina e saúde e de controle demográfico e populacional. A legislação sexual passa a realizar uma política sexual de garantia de direitos sexuais e reprodutivos, que permitem o acesso a direitos por intermédio de identidades forjadas sobre formas específicas de desejos e práticas sexuais, dentro de uma política radical da sexualidade. Desse modo, os dados coletados no Congresso Nacional verificaram a possibilidade da legislação abortiva atual se caracterizar também como um instrumento afirmativo da autodeterminação sexual das mulheres, bem como um meio de proteção da sua liberdade sexual e da sua privacidade, dentro de uma história da política sexual ocidental. Porém, há ainda um forte caráter repressivo dentro da sua temática e restrição da autonomia da mulher na sua tomada de decisão.

\section{BIBLIOGRAFIA}

BUTLER, Judith. Problemas de gênero: feminismo e subversão da identidade. Trad. Renato Aguiar. 8. ed. Rio de Janeiro: Civilização Brasileira, 2015.

BUTLER, Judith; RUBIN, Gayle.Tráfico sexual - entrevista. In: Cadernos Pagu. n. 21. Campinas, 2003, p. 157-209.

D'EMILIO, J.; FREEDMAN, E. Intimate Matters: a history of sexuality in America. 2. Ed. Chicago: University of Chigado Press, 1998.

MATTSON, I.; STROM, K. Parliamentary committees. In: DORING, H. (Ed.).Parliaments and majority rule in Western Europe. Frankfurt: Campus, 1995.

PRECIADO, Paul B. Manifesto contrassexual.Trad. Maria Paula Gurgel Ribeiro. São Paulo: n-1 edições, 2015.

RIOS, Roger Raupp. Para um direito democrático da sexualidade. In: Horizontes antropológicos. Porto Alegre, ano 12, n. 26, p. 71-100, jul/dez. 2006.

ROHDEN, Fabíola. A construção da diferença sexual na medicina. In: Cadernos de Saúde Pública. N. 19, sup. 2. Rio de Janeiro, 2003, pp. 201-212.

RUBIN, Gayle. O tráfico de mulheres: notas sobre a "economia política do sexo". Recife: SOS Corpo, 1993.

SEDGWICK, Eve Kosofsky. Epistemología del Armario. Trad. Teresa Bladé Costa. Barcelona: Ediciones de la Tempestad, 1998.

SGANZERLA, Rogerio. Aborto e Congresso Nacional: uma análise crítica do cenário legislativo. Revista Direito Administrativo \& Constitucional. 2017. Jan-Mar 2017. 